\title{
Researches on the Determination of the Minimum Driving Power of a Fan Operating
} at a Suction Hood

\section{Ioan Andrei Sima ${ }^{1} \&$ Nicolae Băran ${ }^{2}$}

${ }^{I}$ Ph.D. Student, ${ }^{2}$ Prof. Dr. Eng., Faculty of Mechanical Engineering and Mechatronics, Department of Thermodynamics, Engines, Thermal and Refrigerating

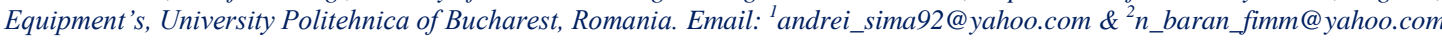

\section{ABSTRACT}

The paper studies the movement of spherical particles to a cyclone, under the action of a stream of air created by a fan; calculation relations are presented to determine the head resistance of a spherical particle in the horizontal and vertical directions. The minimum power of the fan that moves these particles horizontally and then vertically towards the entrance to the cyclone is calculated.

Keywords: Particles, Cyclone, Separation of Particles in the Cyclone, Head Resistance.

\section{Introduction}

Industrial ventilation and air conditioning systems aim to ensure the conditions of air purity and microclimate corresponding to human activity and the nature of the technological process.

The local suction installations through the generated air velocity, achieve a limitation of the spread of harmfulness, ensuring at the same time the minimum openings necessary for the development of technological processes. The used devices must ensure the most complete capture of harmful emissions, do not impede the production process and allow a normal position of the worker, so that it is not between the source of harmfulness and the opening of the suction. These installations consist of the capture device, the cyclone, the fan and the connecting pipes (figure 1). The hoods are local harmful aspiration devices, located above, sideways or below sources [1].

\section{Data about the Studied Particles}

Because the experimental tests will be performed in a laboratory within the Department of Thermotechnics, Engines, Thermal and Refrigeration Equipment's, the laboratory architecture cannot be soiled or destroyed; as a result, no particles of cement, coal dust, sand, etc. will be studied, but plastic particles will be used.

Small particles of medium density polyethylene [2] are considered: $\rho=1250 \mathrm{~kg} / \mathrm{m}^{3}$, spherical in shape with a diameter of $5 \mathrm{~mm}$.

The particle volume will be [3]:

$$
V=4 / 3 \pi r^{3}=4 / 3 \pi 2.5^{3}=4.18 \cdot 15.625=65.31 \mathrm{~mm}^{3}=65.31 \cdot 10^{-9}\left[\mathrm{~m}^{3}\right]
$$

Particle mass: $m_{p}=\rho_{p} \cdot V=1250 \cdot 65.31 \cdot 10^{-9}=81.64 \cdot 10^{-6}=0.081 \cdot 10^{-3}[\mathrm{~kg}]$

Particle weight: $G=m \cdot g=0.081 \cdot 10^{-3} \cdot 10=0.81 \cdot 10^{-3}[N]$

Particle cross-sectional area: $A_{p}=\left(\pi d^{2}\right) / 4=\pi / 45^{2}=19.62 \mathrm{~mm}^{2}=19.62 \cdot 10^{-6}\left[\mathrm{~m}^{2}\right]$ 


\section{Sketch of the Experimental Installation}

The experimental installation is used to study the horizontally, then vertically particles movement. After that, the particles are introduced into a glass cyclone.

The particles placed on a flat plate (8) (figure 1) are driven in horizontal motion by the suction air stream created by the centrifugal fan (2). They enter the cyclone (5) and under the effect of centrifugal force are deposited at the base of the cyclone, and clean air (without particles) is sucked through the pipe (3) by the fan (2) and discharged into the atmosphere through the damper (12). For measuring the air flow rate, a measuring diaphragm has been provided at different operating modes of the installation (4).

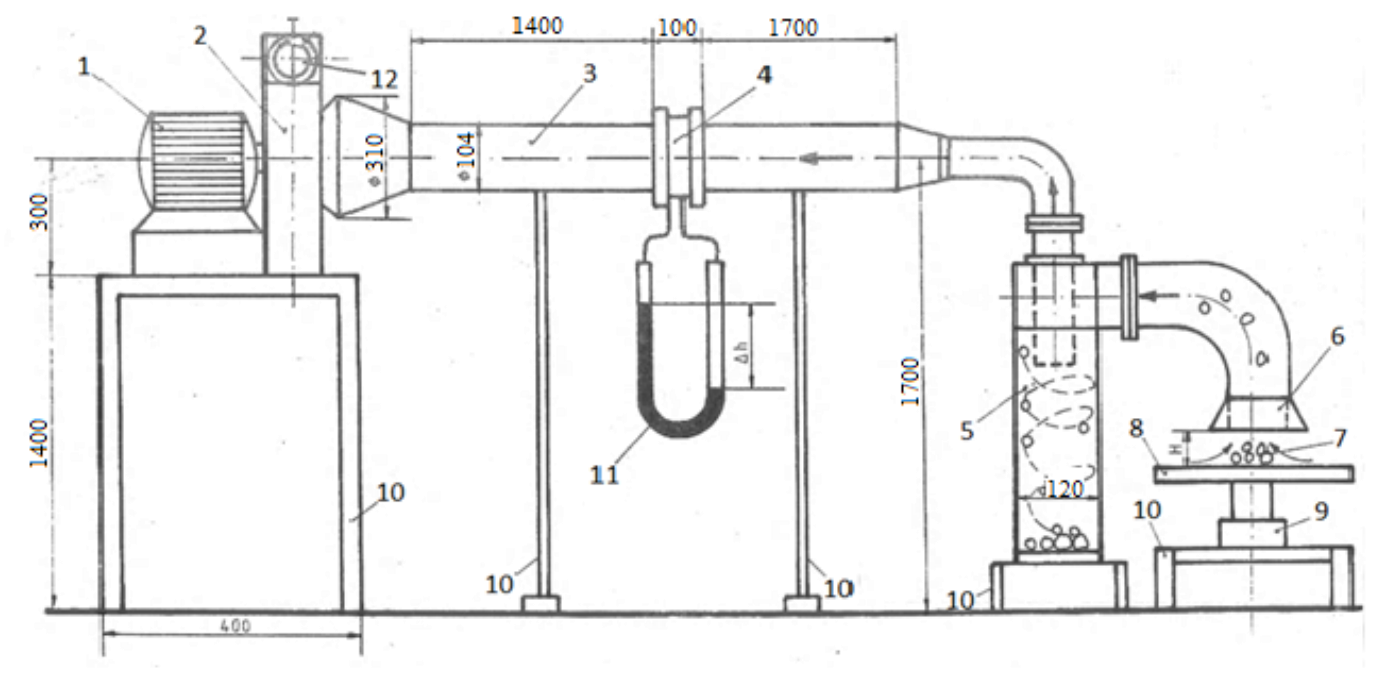

FIG 1: SKETCH OF THE EXPERIMENTAL INSTALLATION

1 - electric motor; 2 - centrifugal fan; 3 - suction pipe; 4 - diaphragm; 5 - cyclone; 6 - suction hood; 7 - particles; 8 - observation plate; 9 - lifting device; 10 - supports; 11 - differential manometer; 12 - damper for regulating the air flow rate

By reading the pressure drop on the diaphragm $(\Delta \mathrm{h})$ from the characteristic curve of the diaphragm, the air flow rate sucked by the fan can be determined.

\section{Horizontally Frictional Movement of the Particle}

The problem is to set a minimum airflow velocity to move a spherical particle in motion on a horizontal surface. The particle can move in two ways:

1- by crawling;

2- by rolling.

The air current act on the particle with a force given by the current velocity that creates a dynamic pressure, which multiplied by the section area of the particle, generates a force $\mathrm{F}$ (figure 2).

According to the action and reaction principle in mechanics, an opposite force $\mathrm{R}_{\mathrm{x}}$ will appear which is the particle horizontal head resistance, i.e. along the $0 \mathrm{x}$ axis (figure 2 ). 


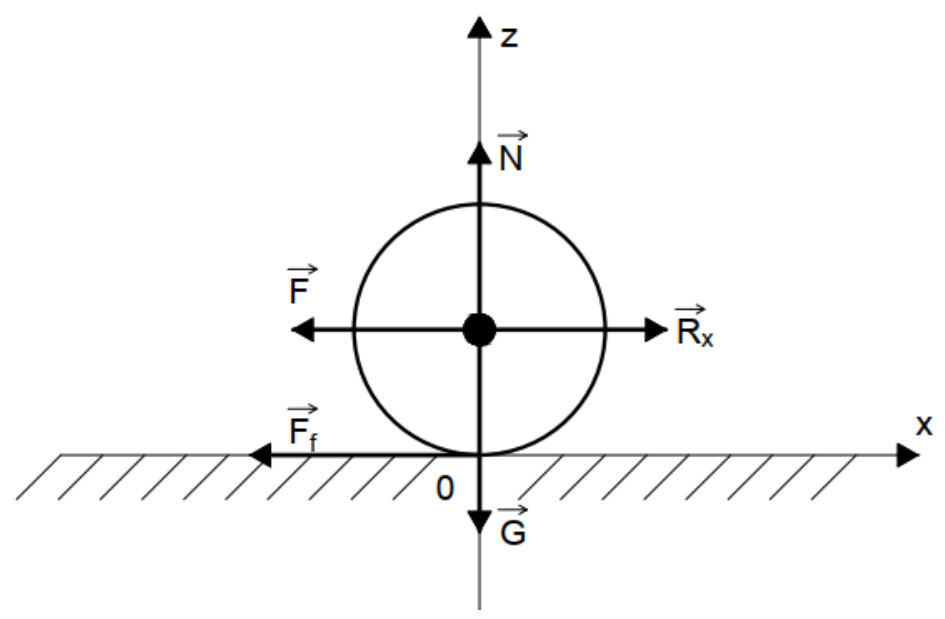

FIG 2: EQUILIBRIUM EQUATION OF THE PARTICLE HORIZONTALLY

The force $\mathrm{R}_{\mathrm{x}}$ is opposed by the friction force between the plane and the particle. On the $0 z$ axis there is the normal reaction to the horizontal plane $(\mathrm{N})$ and the particle weight.

$$
N=G[N] ; F_{f}=\mu \cdot N=\mu m g[N]
$$

The particle will be dragged in motion (the most difficult case compared to a rolling motion of the particle) when the head resistance in the horizontal direction $\left(\mathrm{R}_{\mathrm{x}}\right)$ will be greater than the frictional force between the particle and the observation plate $\left(\mathrm{F}_{\mathrm{f}}\right)$.

$$
R_{x}>F_{f} ; R_{x}>\mu m g[N]
$$

The head resistance on $0 x$, considering the particle as a small sphere [3]:

$$
R_{x}=C_{x} \frac{\rho_{a}}{2} w_{x}^{2} A[N]
$$

where:

$\mathrm{C}_{\mathrm{x}}$ - is the head resistance coefficient to advance along the $0 x$ axis;

$\rho_{\mathrm{a}}$ - air density $\left[\mathrm{kg} / \mathrm{m}^{3}\right]$;

$\mathrm{w}_{\mathrm{x}}$ - the velocity of the air stream in horizontal direction, near the particle $[\mathrm{m} / \mathrm{s}]$;

A - the particle section area, perpendicular to the direction of air flow $\left[\mathrm{m}^{2}\right]$.

The value of $C_{x}$ is [6]:

$$
C_{x}=\frac{24}{R e}\left(1+\frac{3}{16} R e\right)
$$

where the Reynolds number is given by the relation:

$$
R e=\frac{w_{x} \cdot d_{p}}{\vartheta}
$$


where $d_{p}$ is the particle diameter[m].

$$
A=\pi \frac{d_{p}^{2}}{4}\left[m^{2}\right]
$$

\section{Vertically Movement of the Particle}

After entering the hood, in the vertical direction ( $O z$ axis) the particle will move vertically if the head resistance along the ${ }_{0 z}$ axis $\left(R_{z}\right)$ will be greater than the particle weight $(G)$ (figure 3 ).

$$
R_{z}>G
$$

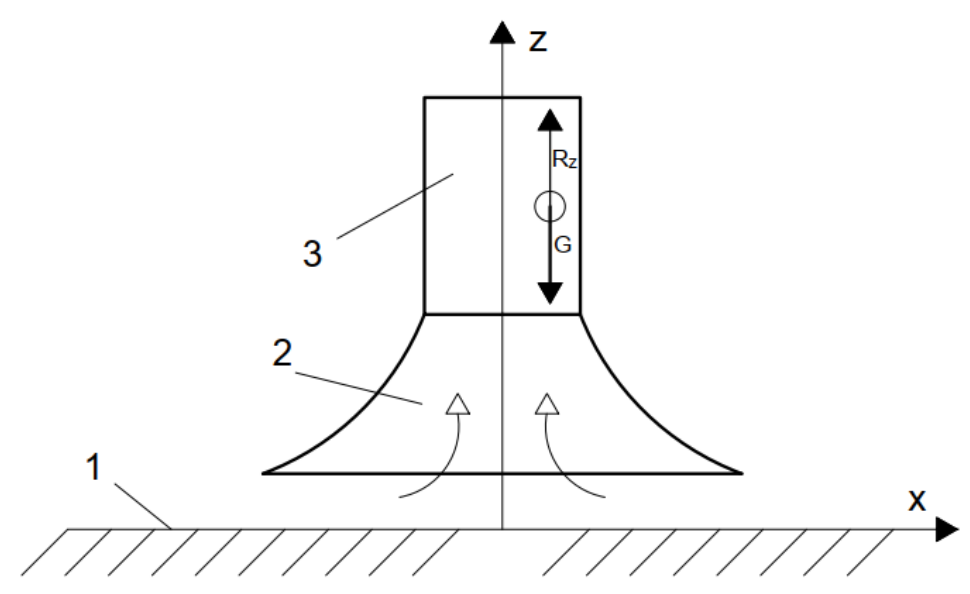

FIG 3: VERTICAL FORCE BALANCE

\section{1 - flat plate; 2 - suction hood; 3 - suction pipe to the cyclone}

It is successively calculated [5][6]:

$$
\begin{gathered}
R_{z}=C_{z} \frac{\rho_{a}}{z_{t}} w_{z}^{2} A_{p}[N] \\
w_{z}=\frac{\downarrow_{z}^{\&}}{\frac{\pi d_{t}^{2}}{4}}[\mathrm{~m} / \mathrm{s}]
\end{gathered}
$$

where:

$\mathrm{d}_{\mathrm{t}}$ - is the diameter of the absorption tube vertically;

$\mathrm{C}_{\mathrm{z}}$ - head resistance coefficient along the $0 z$ axis.

The value of $C_{z}$ is [6]:

$$
\begin{gathered}
C_{z}=\frac{24}{\operatorname{Re}}\left(1+\frac{3}{16} \operatorname{Re}\right) \\
\operatorname{Re}=\frac{w_{z} \cdot d_{t}}{\vartheta}
\end{gathered}
$$




\section{Determination of the Minimum Horizontal and Vertical Particle Transport Velocity}

\subsection{Determination of the Minimum Horizontal Particle Transport Velocity}

Taking into account the shape and dimensions of the particle presented in paragraph 2 , the minimum velocity of the air stream that ensures the horizontal movement of the particle will be determined.

The minimum horizontal particle transport velocity is obtained by equalizing the head resistance $\left(R_{x}\right)$ to the frictional force between the particle and the flat plate [7]:

$$
\begin{gathered}
R_{x}=F_{f} \\
C_{x} \frac{\rho_{a}}{2} w_{x}^{2} A_{p}=\mu \mathrm{m}_{\mathrm{p}} \mathrm{g} \\
w_{x}=\sqrt{\frac{2 \mu \mathrm{m}_{\mathrm{p}} \mathrm{g}}{C_{x} \rho_{a} A_{p}}} \\
w_{x}=\sqrt{\frac{2 \cdot 0.2 \cdot 0.081 \cdot 10^{-8} \cdot 10}{4.5 \cdot 1.2 \cdot 19.62 \cdot 10^{-6}}}=1.74[\mathrm{~m} / \mathrm{s}]
\end{gathered}
$$

\subsection{Determination of the Minimum Vertical Particle Transport Velocity}

The velocity of the air center after the vertical ( $O z$ axis) must create a dynamic pressure on the spherical particle so as to overcome the particle weight.

As a result, the minimum vertical transport velocity for a spherical particle is determined by equalizing the vertical head resistance $\left(R_{z}\right)$ with the particle weight $(G)$.

$$
\begin{gathered}
R_{z}=G[N] \\
C_{z} \frac{\rho_{a}}{2} w_{z}^{2} A_{p}=\mathrm{m}_{\mathrm{p}} \mathrm{g}[\mathrm{N}] \\
w_{z}=\sqrt{\frac{2 \mathrm{~m}_{\mathrm{p}} \mathrm{g}}{C_{z} \rho_{a} A_{p}}} \\
w_{z}=\sqrt{\frac{2 \cdot 0.081 \cdot 10^{-8} \cdot 10}{4.5 \cdot 1.2 \cdot 19.62 \cdot 10^{-6}}}=12.385[\mathrm{~m} / \mathrm{s}]
\end{gathered}
$$

7. Calculation of the Theoretical Driving Power of the Fan When the Particles Move Towards the Cyclone

\subsection{The Required Fan Driving Power for the Particle Horizontal Movement}

For a single particle there are known:

$$
F_{f}=0.08 \cdot 10^{-4}[\mathrm{~N}] ; w_{x}=1.74[\mathrm{~m} / \mathrm{s}]
$$

The power calculation relation is known [3]: 


$$
\begin{gathered}
P=\frac{L}{\tau}=F \cdot w_{m}[W] \\
P=0.08 \cdot 10^{-4} \cdot 1.74=0.139 \cdot 10^{-4}[W]
\end{gathered}
$$

If a number of particles are placed on the circle of radius $r=0.1 \mathrm{~m}$ :

$$
n=\frac{L}{d_{p}}=\frac{2 \pi r}{d_{p}}=\frac{2 \pi \cdot 0.1}{0.005}=125.6
$$

The power consumed for their entrainment:

$$
P=0.139 \cdot 10^{-4} \cdot 125.6=17.45[W]
$$

It is considered that a number of "n" particles are placed near the hood:

$$
P=n \cdot 17.45[W]
$$

For $\mathrm{n}=100$ it results:

$$
P=1745[W]=1.74[k W]
$$

\subsection{Lather the Required Fan Driving Power for the Particle Vertical Movement}

In the case of a single particle there are known:

$$
\begin{gathered}
P=F \cdot w_{z} \\
F=G=0.8 \cdot 10^{-6}[N] ; w_{z}=12.385[\mathrm{~m} / \mathrm{s}] \\
P=0.8 \cdot 10^{-6} \cdot 12.385=9.90[\mathrm{~W}]
\end{gathered}
$$

As in the case of horizontal movement of particles, $n=100$ particles are considered.

$$
P=9.9 \cdot 100=9.9 \mathrm{~W}=0.9[\mathrm{~kW}]
$$

\section{Conclusion}

Both at the horizontal displacement $\left(\mathrm{P}_{0}\right)$ and at the vertical displacement $\left(\mathrm{P}_{\mathrm{z}}\right)$ resulted in the following theoretical powers for driving the fan:

$$
\begin{aligned}
\mathrm{P}_{0} & =1.74[\mathrm{~kW}] \\
\mathrm{P}_{\mathrm{z}} & =0.9[\mathrm{~kW}]
\end{aligned}
$$

In both cases the powers $\mathrm{P}_{0}$ and $\mathrm{P}_{\mathrm{z}}$ are lower than the nominal power of the fan $(\mathrm{P}=3.6 \mathrm{~kW})$, which demonstrates the correctness of the calculations. By finding the minimum power, the electric motor that drives the fan with a minimum power is chosen; as a result, there is a minimum consumption of electricity. 
References

[1] Bancea, Olga, Sisteme de ventilare industrială, Editura Politehnica Timișoara, Timișoara, 2009.

[2] Marinescu, M., ș.a., Mărimi fundamentale în termodinamică, Editura POLITEHNICA PRESS, București, 2003.

[3] Băran, N., Răducanu, P., ș.a., Termodinamică tehnică, Editura POLITEHNICA PRESS, București, 2010.

[4] *** Contract de cercetare științifică nr. 17-8-6/18.08.1998, I.P.B. cu tema "Soluții pentru reducerea concentrațiilor de praf de cărbune din centralele electrice la nivelul concentrațiilor și dispersiilor maxime admise", Beneficiar I.E. Borzești.

[5] Slot, R. E., terminal velocity formula for objects in a viscous fluid, Journal of Hidraulic Research, vol. 22, no. 4, 1984 , p. $235-245$.

[6] Bratu, E., Operații și utilaje în industria chimică, vol. 1, vol. 2, Editura Tehnică, bucurești, 1969.

[7] Florea Julieta, Robescu, D., Hidrodinamica instalațiilor de transport hidropneumatic și de depoluare a apei și a aerului, Editura Didactică și Pedagogică, București, 1982. 